\title{
Early Colon Cancer That Changed Its Morphology Twice
}

\author{
Mitsuhiro Kono, Shusei Fukunaga, Yasuaki Nagami and Yasuhiro Fujiwara
}

Key words: early colon cancer, morphology change, fibrosis

(Intern Med 59: 2961-2962, 2020)

(DOI: 10.2169/internalmedicine.5279-20)

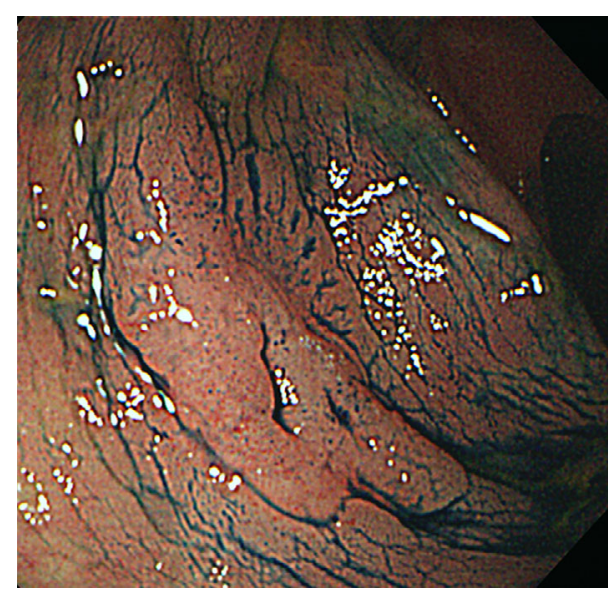

Picture 1.

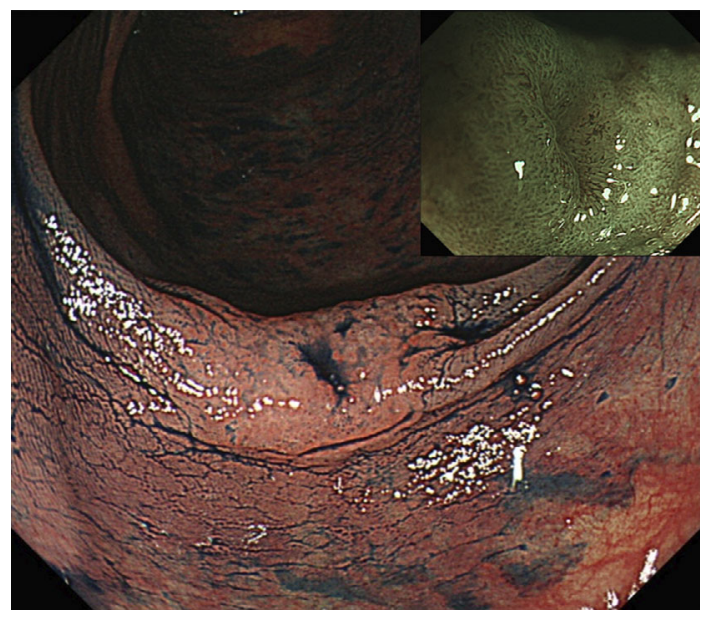

Picture 3.

A 65-year-old man had previously been diagnosed to have a flat lesion measuring $15 \mathrm{~mm}$ in diameter (Picture 1) in the transverse colon. He was referred to our hospital because

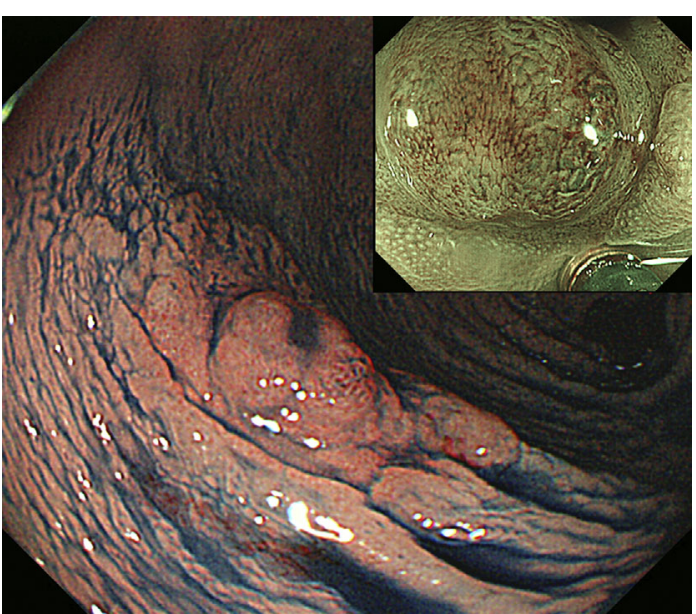

Picture 2.

snaring proved to be difficult after pure saline injection.

At 60 days after being transferred to our institution, a second colonoscopy revealed a nodular protrusion in a shallow depression (Picture 2), thus suggesting the possibility of deep submucosal invasion (1). However, magnifying narrowband imaging (NBI) showed a caliber change and an uneven vessel distribution, which corresponded with the Japan NBI Expert Team classification of type $2 \mathrm{~B}$ disease.

At 92 days after admission, a third colonoscopy before endoscopic submucosal dissection revealed that the nodular protrusion had disappeared and the macroscopic type had changed from IIc+Is to IIa (Picture 3). A histopathological analysis showed minute submucosal cancer invasion (SM1: $230 \mu \mathrm{m}$ ) and partial submucosal fibrosis (Picture 4).

Stimulation by submucosal injection may have induced inflammation followed by fibrosis (2). We hypothesized that the submucosal inflammation reaction had thus caused the protrusion, and thereafter the protrusion gradually diminished along with the remission of inflammation.

Department of Gastroenterology, Osaka City University Graduate School of Medicine, Japan

Received: May 7, 2020; Accepted: June 1, 2020; Advance Publication by J-STAGE: July 14, 2020

Correspondence to Dr. Yasuaki Nagami, yasuaki-75@med.osaka-cu.ac.jp 


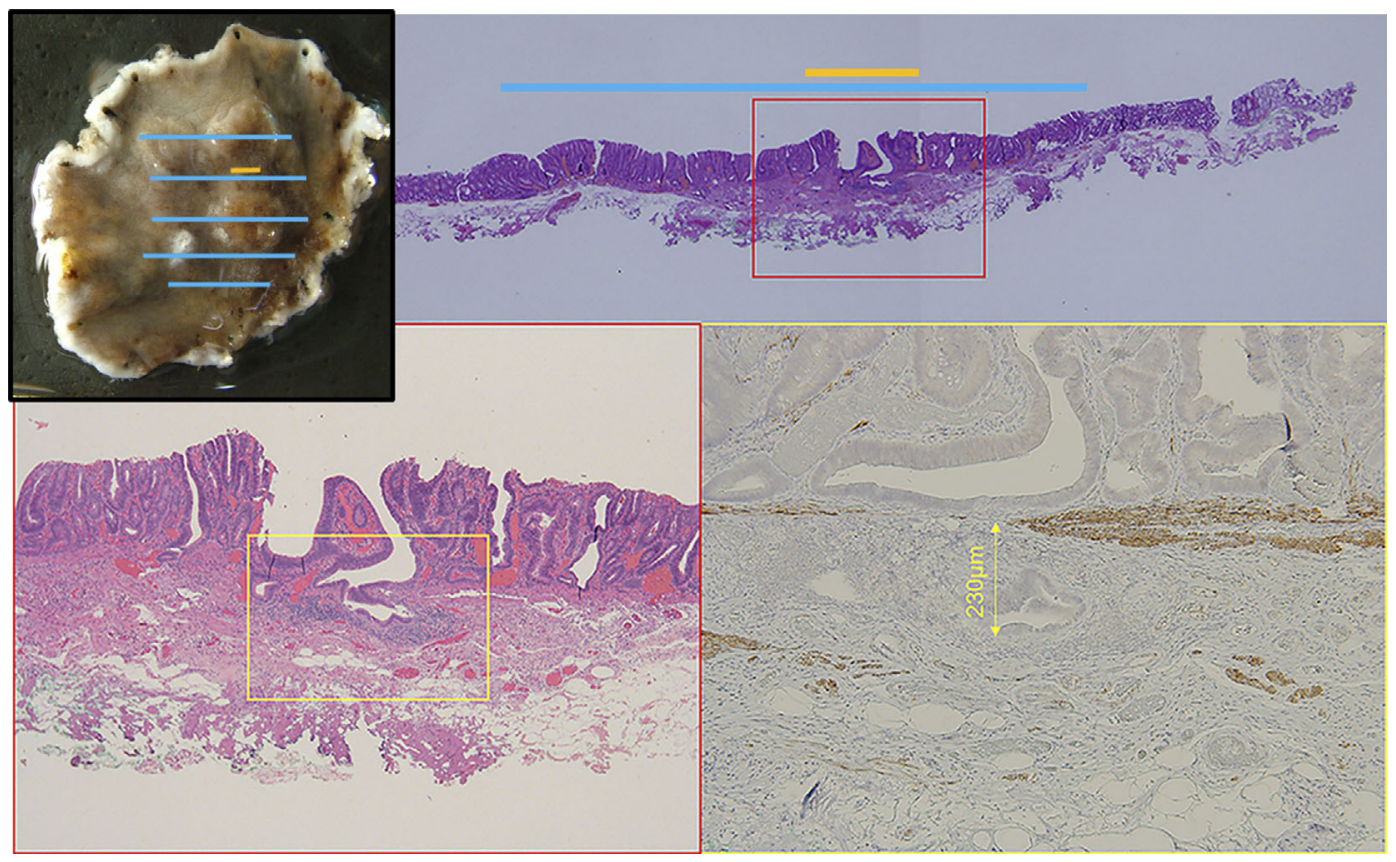

Picture 4.

The authors state that they have no Conflict of Interest (COI).

\section{References}

1. Saitoh Y, Obara T, Watari J, et al. Invasion depth diagnosis of depressed type early colorectal cancers by combined use of video endoscopy and chromoendoscopy. Gastrointest Endosc 48: 362$370,1998$.
2. Fukunaga S, Nagami Y, Shiba M, et al. Impact of preoperative biopsy sampling on severe submucosal fibrosis on endoscopic submucosal dissection for colorectal laterally spreading tumors: a propensity score analysis. Gastrointest Endosc 89: 470-478, 2019.

The Internal Medicine is an Open Access journal distributed under the Creative Commons Attribution-NonCommercial-NoDerivatives 4.0 International License. To view the details of this license, please visit (https://creativecommons.org/licenses/ by-nc-nd/4.0/).

(C) 2020 The Japanese Society of Internal Medicine Intern Med 59: 2961-2962, 2020 